\title{
Contribution to the study of the subcommissural organ of the human fetus
}

\author{
By \\ Kazuyo Shimai and Kinji Suzuki \\ Department of Anatomy, Keio University, School of \\ Medicine, Tokyo, Japan \\ (Director: Prof. Dr. T. Taniguchi)
}

W i s l o c ki and Le d u c (1952) investigated on the subcommissural organ and Reissner's fiber in the brains of several species of rodents (1952) and also in the brain of rats (1954). B a r g m a n $\mathrm{n}$ and $\mathrm{Sch}$ iebler (1952) studied on the same subjects in cats and dogs. These investigators introduced the secretory function of the subcommissural organ in the brains of above mentioned animals by applying the Go mori's chrome alum hematoxylin phloxine method (Gomori 1941) which played a tremendous role on the study of the neurosecretory phenomenon. W is locki and $R$ ot h (1958) had the opportunity to examine the subcommissural organ of a $70 \mathrm{~mm}$ human fetus. In their investigation, they suggested the activity of the secretory function of the subcommissural organ of the human fetus. But their specimen examined in that study is only one. So they state, that the subcommissural organ of older human fetuses and newborns should be examined. We have tried to examine the subcommissural organs of the $195 \mathrm{~mm}, 260 \mathrm{~mm}$ and $275 \mathrm{~mm}$ human fetuses.

\section{Material and Methods}

The material of this investigation is normal human embryos of $195 \mathrm{~mm}, 260 \mathrm{~mm}$ and $275 \mathrm{~mm}$ crown-rump length. After a therapeutic abortion, embryos were fixed with Bouin's or Zenker-formalin solution by intravascular injection. After that, the subcommissural portion was removed from the brain and was refixed with Bouin's or Zenker-formalin solution. The materials were embedded in paraffin, cut at 5 micra thickness. These sections were stained by 
Gomori's chrome alum hematoxylin phloxine (CHP), Gomori$\mathrm{H}$ a $\mathrm{lm}$ i's aldehyde fuchsin staining (AF) (1952) and M c M a n u s' periodic acld-Schlff stalning (PAS) (1946) for recognition of glycogen and mucopolysaccharide. A control sections for identification of glycogen, some sections were immersed in $1 \%$ diastase solution for one hour before the proceeding of the PAS staining.

\section{Observations}

The subcommissural organ of the human embryo is located beneath the pineal recess and posterior commissure. The ependymal layer of the subcommissural organ faces the cranio-posterior area of the third ventricle. The ependymal layer of the subcommissural organ of the human fetus consists of tall columnar ependymal cells. The ependymal layer of this organ is deeply bluish stained by Go m or i's CHP method. When observed in detail, the columnar cells of the ependymal layer include fine granules diffusely scattered in their cytoplasm. These fine granules are stained deeply bluish with the CHP method and appear to be dustlike. Especially, at the supranuclear portion of the cytoplasm or on the surface of the ependymal cells, fine dot-like granules are found (Figs. 2 and 3). The Go mor i-H a l mi's method stains also fine granules in the apical portion of the cytoplasm of the ependymal cells. The stainability of the granules seen by the AF method is faint (Figs. 4 and 5). The distribution, size or quantity of $\mathrm{AF}$ positive granules in the cytoplasm are similar to those of CHP positive granules. Some of the ependymal cells have cilia (Fig. 2). In these cilia the existence of the CHP or AF positive substance is not so distinctly observed. The cilia is not stainable by the CHP or AF technique. In places of the surface of ependymal cells, a cloud-like substance which is stained homogenously by the CHP or AF method is seen. The cloud-like substance does not contain any distinct granular material. By the application of the PAS reaction, the subcommissural organ is stained deeper than the surrounding tissue (Fig. 1). The cytoplasm of the ependymal cells is stained fine granular by the PAS method (Figs. 6, 7 and 8). The size of PAS positive granules is rather larger than that of CHP positive granules. The PAS positive granules in the cytoplasm are distinctly seen especially in the supranuclear portion of the ependymal cells. Upon staining with the PAS method after the examination of digestion 
by $1 \%$ diastase solution, the cytoplasm of ependymal cells is partly stained and granular. The so called "Reíssner's flber" is not found upon the surface of the subcommissural organ or in the third ventricle of the examined fetuses.

\section{Discussion}

$\mathrm{Wi}$ i locki and Roth (1958) investigated the selective stainability of the $70 \mathrm{~mm}$ human fetus subcommissural organ by CHP, $A F$ and PAS methods. In that paper, they discribed, that the subcommissural organ of the $70 \mathrm{~mm}$ human fetus is functionally active and the fine granules, which are bluish stained by the CHP or AF method, in the cytoplasm of the ependymal cells of the subcommissural organ are somewhat similar to the neurosecretory granules produced in the hypothalamic nuclei. Moreover, they have suggested, that these $G$ o mor i positive fine granules may contain a mucoprotein or mucopolysaccharide upon staining with the PAS method. According to our observation, in the cytoplasm of ependymal cells, there are fine granules stained by the CHP or AF method. These fine granules scatter diffusely in the cytoplasm, and especially, in the supranuclear region of the cytoplasm, granules are more or less larger and thicker than in the other portion of the cytoplasm. Go mori-positive fine granules are not so distinctly seen upon the surface of the ependymal cells or among the cilia. The whole subcommissural organ shows relatively strong activity of the PAS reaction. The cytoplasm of the ependymal cells is stained more distinctly granular by the PAS staining, than by the CHP or AF staining. After immersion in $1 \%$ diastase solution for one hour, the cytoplasm of the ependymal cells shows partly active reaction by the PAS reaction. The cytoplasm of the ependymal cells might be containing mucoprotein or polysaccharide. Recently, T a l a n t i (1959) investigated the developmental study of the subcommissural organ of the bovine fetus. In his report, he stated that, the secretory material in the subcommissural organ is already existing at the age of a three months bovine fetus. That.is, the subcommissural organ of the bovine fetus is functionally active by the third month. This fact was concluded also by the result of the recognition of the enzymatic activity in the organ. Talanti also says, that the secretory material in the subcommissural organ of the bovine fetus seems to increase in amount up to the 7 th month. Our materials 
belong rather to the latter stage of the intrauterine month, than that of $W$ is locki and $R$ ot h's material. In spite of such stage of fetuses, the formation of the Gomori-positive granules is not so remarkable. In comparison with the granules of the ependymal cells of the subcommissural organs among three fetuses examined by us, there is no evident difference in stainability, size and quantity. The functional activity of the subcommissural organ of the human fetus might be considerable also from the result of our observation obtained in this investigation. However, histologically, we consider, that our findings are not enough to explain the active secretory phenomenon of the human fetus subcommissural organ.

\section{Summary}

This investigation was done concerning the functional activity as a secretory organ of the $195 \mathrm{~mm}, 260 \mathrm{~mm}$ and $275 \mathrm{~mm}$ human fetus subcommissural organs. In the cytoplasm of the ependymal cells, CHP or AF positive fine granules are found, but upon the surface of the ependymal cells or among the cilia, there are no such distinct granules. The cytoplasm of the ependymal cell in the subcommissural organ seems to be containing mucoprotein or polysaccharide. However, histologically, the identification of the secretory phenomenon of the ependymal cells is not so distinct in the subcommissural organ of the human fetus examined in this investigation.

\section{Literatures}

1. B a rgmann,W. and T.H.Schiebler: Histologische und cytochemische Untersuchungen am Subkommissural Organ von Säugern. Zeitschr. f. Zellforsch., 37 : 582-596, 1952.

2. Gomori, G.: Observation with differential stains on human islets of Langerhans. Am. J. Path., 17 : 395-406, 1941.

3. Halmi, N.S.: Differentiation of two types of basophils in the adenohypophysis of the rat and mouse. Stain tech., 27: 61-64, 1952.

4. McManus, J.F.A.: Histological demonstration of mucin after periodic acid. Nature, 158: 202, 1946.

5. Ta lanti, S.: Studies on the subcommissural organ of the bovine fetus. Anat. Rec., 134 : 473-489, 1959.

6. Wislocki, G.B. and E.H. Leduc: The cytology and histochemistry of the subcommissural organ and Reissner's fiber in rodents. J. comp. Neur., 97 : 515542, 1952.

7. W is locki, G. B. and E. H. Leduc: The cytology of the subcommissural organ, 
Contribution to the study of the subcommissural organ on the human fetus 399

Reissner's fiber, periventricular glial cells and posterior collicular recess of the rat's brain. J. comp. Neur., 101: 283-309, 1954.

8. W is $10 \mathrm{cki}, \mathrm{G}$. B. and W.D. Roth: Selective staining of the human subcommissural organ. Anat. Rec., 130: 125-133, 1958.

\section{Explanation of Figures}

Fig. 1. Longitudinal section of the subcommissural organ of the human fetus: PAS method. $400 \times$.

Figs. 2 and 3. Gom or i's CHP stain. In the cytoplasm of the ependymal cells, dustlike fine granules which are stained chrome-hematoxylin are found. On the apical surface of the epithelial cells there are dot-like CHP positive granules. $900 \times$.

Figs. 4 and 5. Gomori-Ha $1 \mathrm{mi}$ 's AF stain. In the cytoplasm, fine granules are seen. These granules show the AF positive stainability. Note, the tiny particlelike granules are located, making a dotted line, along the apical surface of the cytoplasm of the ependymal cells. $900 \times$.

Figs. 6-8. PAS reaction. Relatively small PAS positive granules are found in the cytoplasm, especially on the upper portion of the nucleus. Generally, a whole organ reacts relative strongly by the PAS staining.

Figs. 9 and 10. Control sections, immersed in 1\% diastase solution for one hour before proceeding of the PAS method. The cytoplasm of the ependymal cells are partly reactive. The PAS positive tiny granules in the cytoplasm are not so distinct. Generally, the activity of the PAS reaction in the cytoplasm of the ependymal cells decreases slightly. 

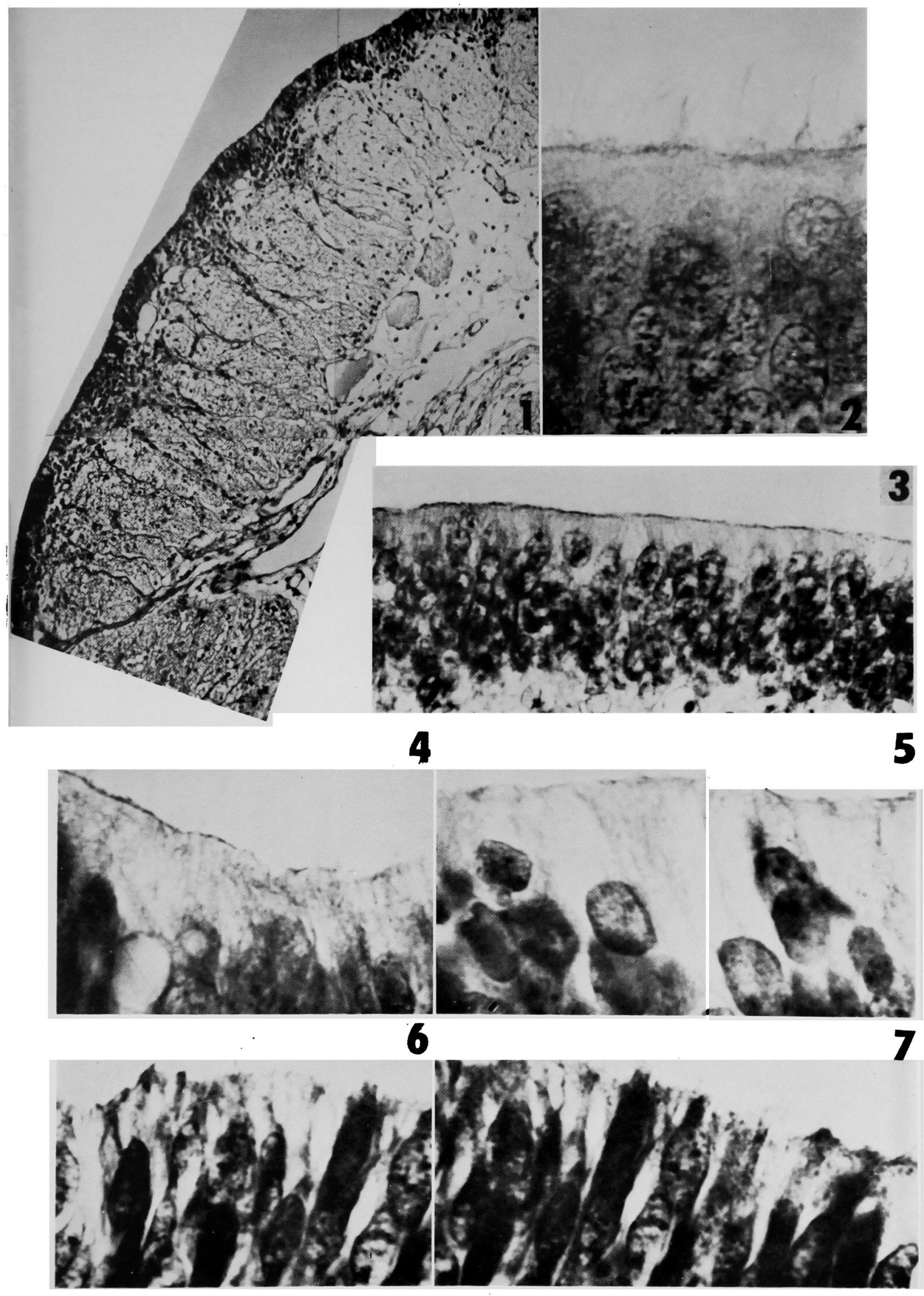

K. Shimai and K. Suzuki 
Plate II
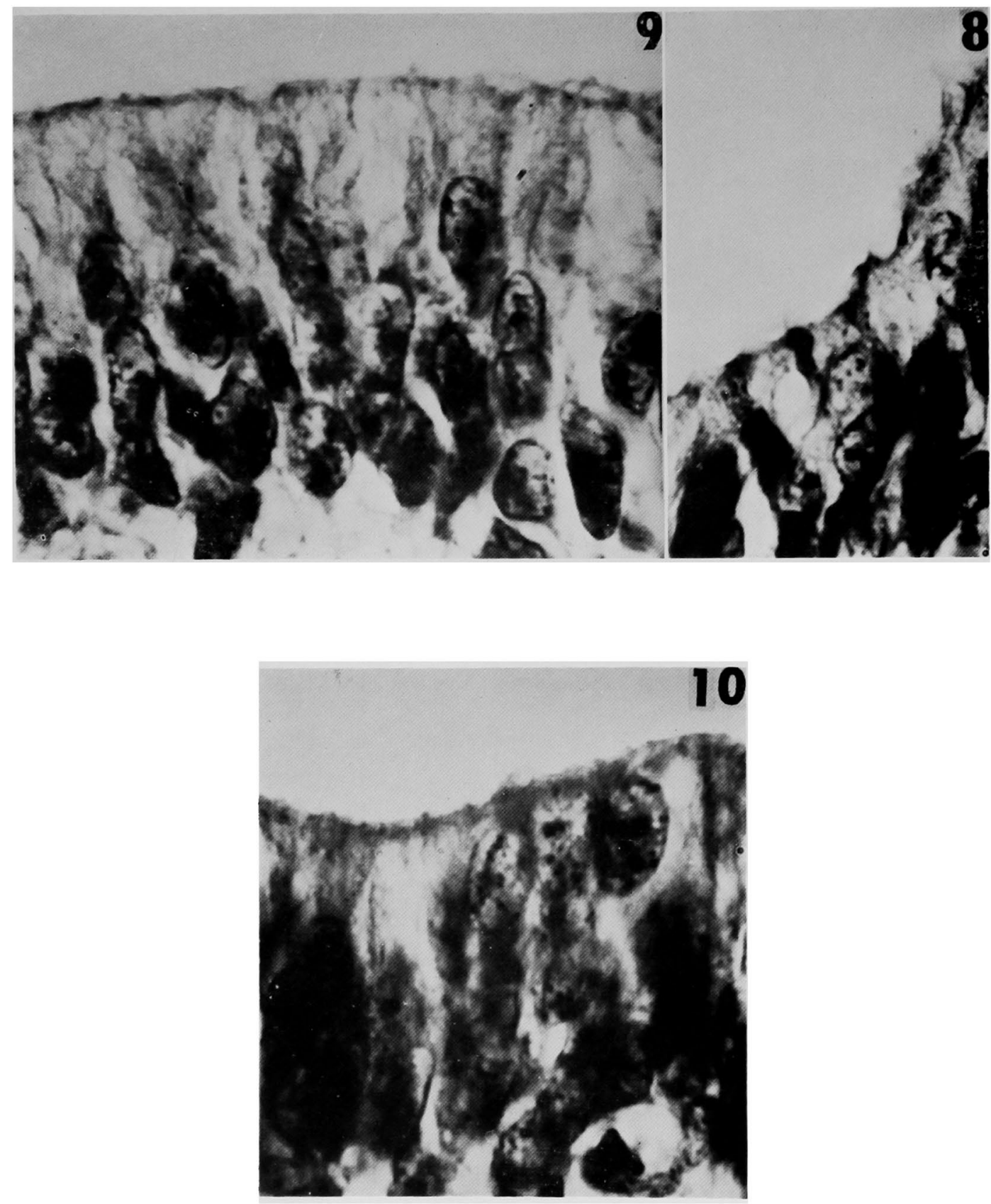

K. Shimai and K. Suzuki 